IN FOLIO 


\title{
De biografías y arcontes: las potencialidades del archivo colonial
}

\author{
Por Betina Sandra Campuzano \\ Universidad Nacional de Salta
}

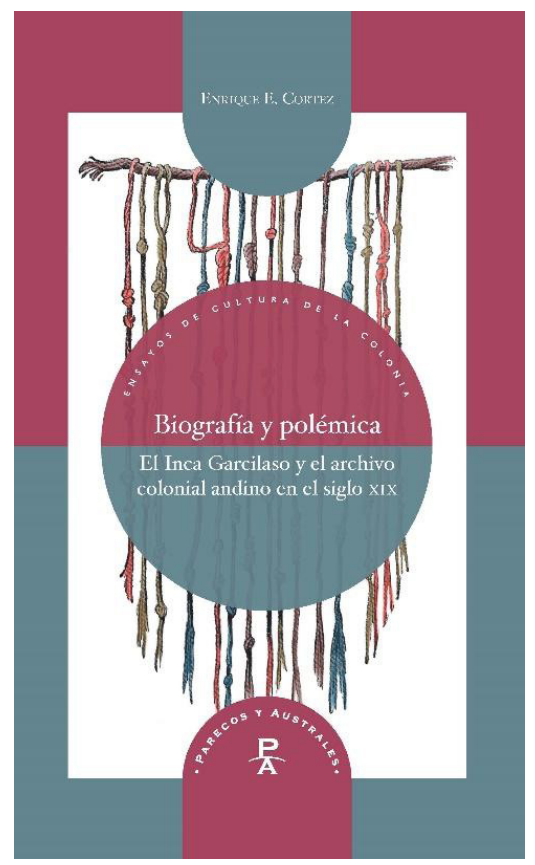

Enrique E. Cortez. Biografía y polémica. El Inca Garcilaso y el archivo colonial andino en el siglo XIX. Madrid: Iberoamericana-Vervuert, 2018. 344 págs.

En los años noventa Antonio Cornejo Polar, al prestar atención a las últimas tres décadas confusas en el Perú, señaló con lucidez la insuficiencia de las categorías del hispanismo, el indigenismo y el mestizaje para abordar y dar respuestas a la cuestión de las identidades nacionales en los tiempos recientes atravesados por procesos migratorios y fenómenos de la violencia. Instaló asimismo una sospecha: las identidades nacionales son, en realidad, un falso problema construido por una o varias élites intelectuales. Y este falso problema es puesto en jaque tanto por la aparición de figuras fragmentarias y migratorias, como por los debates en torno a la ciudadanía y los desplazamientos poblacionales. Aunque refiriéndose a un tiempo anterior, esto es, a un convulso siglo XIX que revisita la obra garcilasista, la propuesta de Enrique Cortez, a propósito de las lecturas en torno a los Comentarios reales del Inca Garcilaso, bien puede esbozar un nuevo camino ante la encrucijada de categorías críticas que resultan hoy insuficientes no solo para abordar los textos contemporáneos sino, y sobre todo, para aquellos producidos y leídos en los tiempos republicanos.

De este modo, al mismo tiempo que da cuenta de cómo han madurado el interés y la trayectoria académicos del autor en torno a la obra garcilacista, la reciente publicación de Biografía y polémica. El Inca 
Garcilaso y el archivo colonial andino en el siglo XIX de Enrique Cortez evidencia una serie de avances e innovaciones teóricas y metodológicas que revitalizan el campo de los estudios coloniales, como también traza un camino metacrítico que pone al descubierto las formas en que se han construido las historias de la literatura y los imaginarios nacionales. Hay en esto último un gesto que nos recuerda las sospechas cornejopolarianas y que, de algún modo, también arriesga una respuesta: "A diferencia del argumento eurocéntrico de González Echevarría, según el cual el archivo contendría el origen mítico de la cultura latinoamericana como una derivación de las leyes imperiales que reúne; mi aproximación sostiene que la relevancia del archivo radica en su condición de ser un lugar de enunciación que instala y legitima discursos en competencia sobre la cultura y la historia en América", nos advierte Enrique Cortez (2018: 51). A partir de este contraargumento que discute que se considere solo el carácter imperial como aquel que configura el archivo latinoamericano y a través de él se argumente la superioridad europea, Cortez sugiere la presencia de tres tendencias que se hallan en tensión y diálogo desde la aparición del archivo latinoamericano: la imperial, la criolla y la indígena. Con esto, quiero señalar cómo Cortez de algún modo, por sus propios derroteros, también está volviendo sobre la misma sospecha que sugiere Cornejo Polar: no alcanza solo con la tendencia imperial (la criolla o la indígena) para dar cuenta de la configuración de los imaginarios nacionales continentales; al contrario, es en la intersección de tales modalidades que recién puede revisitarse el imaginario nacional.

Existe un consenso general entre los críticos literarios que destaca el prolífico caudal y los numerosos enfoques adoptados en los estudios de la obra garcilasista; sin embargo, el abordaje que realiza Enrique Cortez en Biografía y polémica... cubre un área de vacancia al acercarse a un periodo poco explorado. Si bien lo conocemos como el siglo XIX, Cortez también esboza una propuesta diferente de periodización que, frente a los cortes centenarios, atiende más bien a un proceso comprendido entre 1780 y 1930, en el que se desarrolla la conformación de los proyectos nacionales. En este sentido, Biografía y polémica... se erige como una propuesta innovadora no solo porque retoma el bagaje de la crítica literaria garcilasista configurándose así como un proyecto metacrítico en sí mismo, sino también porque realiza un corte diacrónico que da cuenta del modo en que se comunican entre sí diferentes temporalidades históricas: la colonial con la obra del Inca Garcilaso, la decimonónica con las lecturas de los intelectuales que intervienen en la conformación de las historias de las literaturas nacionales y los proyectos de conformación de Esta- 
dos y, por supuesto, los ecos que estas lecturas tienen en el presente de la crítica.

El estudioso peruano radicado en EE.UU. plantea, entonces, una serie de innovaciones tanto teóricas como metodológicas para abordar un corpus de lecturas de diversos intelectuales republicanos, en torno a la obra garcilasista: William Prescott, Marcelino Menéndez Pelayo, Manuel González de la Rosa, José Toribio Polo y José Riva Agüero. El resultado de esta investigación, sin duda, vigoriza y fortalece los estudios coloniales volviendo sobre un corpus fundacional como el garcilasista en un área de vacancia dentro del campo: el siglo XIX. Hay en este recorte y en la elección de la forma de abordaje, además, otro gesto que también da cuenta de una apertura del concepto canónico de literatura: atender a los modos de leer de los que nos habla Roger Chartier como "formas de estar en sociedad", aunque el propio Cortez no lo enuncie ni lo entienda en estos términos. Es decir, advierto que esta empresa metacrítica que desarrolla el crítico peruano está volviendo, entre otras cosas, sobre los "modos de leer" de unas sociedades, sobre sus conceptualizaciones y los posicionamientos de sus lectores.

Para trazar este camino metacrítico, Cortez recurre a las conceptos de "biografía" y "archivo" que son, a la vez, propuestas teóricas pero también metodológicas. Asimismo, organiza el trayecto a partir de una estructura muy clara y ordenada: parte de una imprescindible introducción que no solo da una cartografía del abordaje posterior, sino que expone un breve pero contundente estado del arte (tarea nada sencilla, dada la proliferación de estudios garcilasistas) y presenta las líneas y los conceptos teóricos a los que ha recurrido. Luego, ordena la información en dos partes a las que organiza según la procedencia y la temporalidad de los lectores del Inca Garcilaso en el siglo XIX: la primera, refiere a la recepción en EE.UU. y en Madrid a partir de las figuras de Prescott y de Menéndez Pelayo, como también al modo en que se construye el archivo colonial andino. Si con la primera, Cortez descubre que el campo de los estudios coloniales, tal como lo conocemos hoy, se inicia con la lectura del norteamericano que reclasifica la obra del Inca debilitando su posición como historiador, con la segunda figura Cortez observa la canonización del productor mestizo dentro de las arcas literarias hispánicas y de esta manera su reclasificación como novelista. Ello no resulta un hecho irrelevante: al contrario, el interés de Menéndez Pelayo por incorporar la obra garcilasista dentro de una historia de la literatura hispánica no deja de responder a un propósito imperialista y eurocéntrico, pues el continente conquistador aún libra la batalla por imponer su 
superioridad precisando la incorporación de una figura americana en su canon.

En una segunda parte, Cortez conduce la polémica en torno a la obra del Inca a la recepción que esta posee entre sus coterráneos durante la segunda parte del siglo XIX y la primera del XX. Aquí, el crítico atenderá al modo en que los "arcontes" peruanos reciben la obra garcilasista y la ponen en funcionamiento en un proyecto que es, a todas luces, la exaltación de un mestizaje armónico -como diría Cornejo Polar- y, por lo tanto, hispánico. Finalmente, el epílogo que plantea Cortez nos permite recuperar los resultados de la investigación a partir de lo que será el gran aporte de esta escritura: las potencialidades que subyacen en la noción foucaultiana de "archivo", a la que el crítico peruano no duda en calificar como "colonial" y "andino". En este apartado, además, Cortez pone en diálogo el "archivo colonial" que se construye desde la colonia y que halla sus ecos en el momento republicano, al tiempo que introduce los diálogos con el archivo más reciente: la escritura literaria arguediana, las lecturas críticas de Cornejo Polar y la relevancia contemporánea de autores como Guaman Poma para los actuales estudios coloniales.

Además, Biografía y polémica ... presenta otras innovaciones más que se despliegan en diferentes sentidos: en cuanto a su propuesta metodológica, Cortez propone tanto los conceptos de "biografía" como de "archivo" para lo que, por un lado, debe desaprender los preconceptos con los que los estudios literarios hasta hoy han abordado el aspecto biográfico. Y, por otro, debe retomar y reformular propuestas anteriores acerca del "archivo" — como las de Roberto González Echevarría y Diana Taylor, quienes consideran que se trata de una propuesta tanto teórica como metodológica- para reescribir la historia nacional. La metodología del "archivo" no imagina un canon terminado o inamovible, sino que, al contrario, muestra el potencial para deconstruir lo canónico y la valoración cultural. En lo que respecta al campo de los estudios coloniales y su alcance teórico, la novedad precisamente consiste en dar una vuelta de tuerca a la noción de "archivo", que permite no solo continuar con las reflexiones y las clasificaciones que, en los años ochenta, realizaron pioneros como Walter Mignolo y Rolena Adorno, sino que también avanza hacia nuevas formas de organizar los textos coloniales andinos, pone en jaque un canon hasta ahora no cuestionado y prospera en la reflexión de una propuesta foucaultiana que, aun con todos los riesgos de las extrapolaciones, pueda operativizarse en el corpus americano.

Resulta también novedoso el tratamiento que Cortez realiza de la obra garcilasista y el imaginario republicano a partir del estudio de 
las lecturas de lo que llama los "arcontes": son aquellos que, antes que meros "archivistas", resultan los guardianes del archivo y encierran su dimensión política. Cortez propone aquí esta categoría que, en mi opinión, resulta valiosísima y es, del mismo modo, potencial para los estudios literarios y culturales latinoamericanos. Incluso, creo que la figura del "arconte" bien podría entroncarse con otras tales como el "letrado solidario" de Hugo Achúgar o el "agente social" de Ricardo Costa y Teresa Mozejko, tanto por su complejidad en los pliegues de la mediación, como por las potencialidades enunciativas que en ella residen.

Sin duda, Biografía y polémica... pone en jaque ciertas categorías estancas que la crítica desarrolló otrora y sobre las que no necesariamente ha vuelto para cuestionarlas. En este sentido, Cortez está esbozando nuevas respuestas a los estudios literarios andinos y a los coloniales cuando propone avanzar sobre la recepción de los lectores fundacionales del proyecto de nación continental; como también lo hace al replantear las discusiones de algunos pensadores latinoamericanos que han funcionado como vectores: Roberto González Echevarría, Diana Taylor, Walter Mignolo y Rolena Adorno, por ejemplo. Actualiza también sus lecturas de Cornejo Polar y de Arguedas sobre la figura, la biografía y la obra del Inca Garcilaso de la Vega. Como bien lo señala en el epígrafe que corresponde a los Comentarios reales..., son estos mismos textos "archivos" o relaciones de sus historias, las que están lejos de entenderse en términos armónicos o mestizos, sino que deben pensarse a través de la superposición de las tendencias imperial, criolla e indígena. Es esto lo que tanto Cornejo Polar como Arguedas, aunque ambos lejos de una lectura foucaultiana, advierten como un avance dentro del campo de estudios. De algún modo, Cortez -al igual que Prescott, Menéndez Pelayo o Riva de Agüero, como también puede suceder con Cornejo Polar o José María Arguedas- resulta un estilo de "arconte" que habla de la colonia, del tiempo republicano y, sobre todo, de nuestro presente. $Y$ es que, justamente, en eso reside la potencialidad del "archivo": en el modo en que puede transmitirse la memoria que no es solo letrada sino también popular y corpórea. Y es que el "archivo" es eso: práctica de mediación, de traducción y transcodificación de la memoria. Y el "arconte" es, quizás, el traductor o el editor que nos permita salirnos de los procesos de identificación y las categorías obturadas. 